\title{
COMUNIDAD DIFERENCIADA. LINCHAMIENTO POR BRUJERÍA E IMAGINARIOS POLÍTICOS EN UN PUEBLO TOJOLABAL
}

\author{
Astrid Pinto Durán \\ Martín de la Cruz López Moya
}

\section{Introducción}

$\mathrm{R}$ etomando la voz de los tojolabales, "hombres verdaderos", Carlos Lenkersdorf señaló en uno de sus textos que se ha vuelto referencia en el estudio de este grupo mayense: "Todos somos sujetos. Todos somos responsables los unos de los otros. No hay nada que no tenga corazón. Por ello todos nosotros y todas las cosas vivimos y formamos una comunidad cósmica de consenso de todos los vivos" (Lenkersdorf 1996:74).

Estas ideas elaboradas a partir de un análisis lingüístico se sostienen sobre la tesis de que el tojolabal es una lengua "intersubjetiva", lo que en términos gramaticales equivale a decir que no existe la presencia de objetos directos o indirectos (Lenkersdorf 1996:45). ${ }^{1}$

Lo que nos interesa debatir en este artículo no son estas cuestiones lingüísticas, sino las conclusiones a las que el autor llega respecto a la sociedad y cultura tojolabal, pero también al método. Lenkersdorf señala en el texto en discusión que su interés es acceder, a partir del estudio de la lengua, a la cosmovisión de este grupo, es decir, a cómo "lo real" es visto por los tojolabales. Aunque en el texto no es difícil percibir su mirada ajena a esta cultura,

Astrid Pinto Durán y Martín de la Cruz López Moya, CESMECA-UNICACH. propone que para comprender la cosmovisión tojolabal, hay que convertirse irremediablemente en uno de ellos.

Casi "convertido" en tojolabal, Lenkersdorf resume la intersubjetividad como sigue: "Todos somos sujetos, como tales vivimos y formamos una comunidad de consenso. Por consiguiente somos responsables los unos de los otros, responsables de esa comunidad cósmica de vida a la cual pertenecemos" (Lenkersdorf 1996:75) Para este autor, la noción de comunidad no puede entenderse sin la de intersubjetividad, que nos remite a la realidad social, natural y cultural.

Lenkersdorf nos presenta una sociedad tojolabal sin fisuras, homogénea, llana, ilesa de los procesos históricos que ha vivido la región; pretende hacernos ver una cultura que resiste desde hace 500 años, en oposición a una sociedad dominante, como si se tratara de dos mundos aparte y como si la sola fuente de conflictos para los tojolabales viniera de esa relación.

Esta armonía e igualdad toca prácticamente todos los aspectos de la vida social. Por ejemplo, al referirse a la asamblea afirma:

Los dirigentes verdaderos reciben todo el respeto porque saben articular el pensamiento de la comunidad. Como algunos dicen mandan obedeciendo y no mandan mandando. La toma de decisiones, pues, 
está en manos de la comunidad. Las autoridades sólo las "verbalizan". De este modo se evidencia que la decisión definitiva no depende de una sola persona, tampoco de la mayoría, sino de todos. Se refiere, pues, al consenso unánime (Lenkersdorf 1996:81).

Los tojolabales, según este autor, no compiten. La competitividad es una característica exclusiva de nuestras sociedades capitalistas. El principio es que, entre los tojolabales, todos somos iguales:

Una asamblea realizada por tojolabales nos señala la intersubjetividad en el contexto social, mejor dicho, político social. Nos hace ver la forma de democracia, sea directa o representativa, que corresponde a la idiosincrasia tojolabal. La intersubjetividad se hace concreta en el contexto sociopolítico. Como tal exige el consenso unánime en lugar del régimen de la mayoría. Requiere que todos se sepan incluidos en el nosotros de la decisión final. Así se manifiesta la intersubjetividad del lajan lajan 'aytik. Todos somos iguales. Todos somos sujetos. Se necesita la voz de cada uno para que se logre el consenso válido (Lenkersdorf, 1996:82).

Nos hemos permitido exponer las principales nociones que guían las reflexiones de este autor porque nos interesa, en las siguientes líneas, aportar otra mirada hacia este grupo que ha sido muy poco estudiado. En este ver de otro modo, se cuestiona inevitablemente la idea de que los tojolabales y nosotros los occidentales vivimos como grupos separados y antagónicos. Nos parece que es demasiado restringido hablar de una cosmovisión homogénea, de una intersubjetividad compartida por todos y exenta de la "contaminación exterior" y del paso del tiempo. Lejos de la armonía, presentamos una sociedad inmersa en conflictos y luchas, y con una creciente diferenciación y competitividad; partícipe, además, de las tensiones y problemáticas regionales, y cuestionamos la supuesta igualdad que priva entre los tojolabales, así como las ideas de la comunidad de consenso y de la asamblea comunal como ejercicio político de unanimidad.

Estamos conscientes de que se trata de una interpretación. Sin ser tojolabales podemos dialogarcon ellos desde donde estamos y con lo que somos. Nuestro método será relatar un suceso ocurrido en octubre de 1997 en El Vergel, una comunidad del municipio de Las Margaritas, Chiapas. ${ }^{2}$ Se trata de siete campesinos quienes, tras ser acusados de participar en el robo de ganado y de practicar la brujería, fueron ejecutados como resolución de un "acuerdo" de la asamblea local.

Aunque este linchamiento ocurrió hace varios años, su debate continúa siendo vigente, pues nos obliga a volver la mirada hacia este grupo cuya posición geográfica y cultural es estratégica para comprender los procesos políticos que ha vivido la región desde hace varias décadas.

Además, a pesar de que el linchamiento por brujería continúa siendo una práctica cultural admitida para la resolución de conflictos en el medio rural y, cada vez más en el medio urbano, pocos trabajos antropológicos han tomado este fenómeno como punto de discusión y sólo aparece como un recurrente dato etnográfico. En la radio de las diversas localidades de Chiapas y Guatemala, los asesinatos por prácticas de brujería son noticia corriente. Éstos suceden por lo general en el medio rural o en el contexto de las localidades indígenas. Sin embargo, con más frecuencia se sabe de casos de linchamientos por éstas y otras causas en ciudades como Comitán, Teopisca y San Cristóbal de Las Casas, con una importante población de migrantes indígenas. ${ }^{3}$

El linchamiento como fenómeno social merece ser estudiado en sus múltiples facetas y causas, pues estos constituyen una forma de violencia colectiva bastante extendida en diversas partes del país, en zonas rurales y urbanas. $^{4}$

Literatura antropológica reciente sobre Chiapas ha tomado como tema de debate los linchamientos 
asociados a historias de "cortacabezas". ${ }^{5}$ Graciela Freyermuth (2002) considera que este fenómeno social está relacionado con el enriquecimiento desmedido o con la adopción de una conducta no aceptada socialmente. La autora toma como ejemplo la ejecución de siete indígenas en Chenalhó, Chiapas, por ser considerados "cortacabezas", y concluye que estas narraciones son indicativas de los procesos de diferenciación y conflicto surgidos de nuevos escenarios políticos, y económicos. "Los linchamientos y los hechos ocurridos antes de 1997, asociados a historias de "cortacabezas" son expresión de las formas comunitarias que se ponen en juego para la resolución de conflictos y el control social (Freyermuth, 2002:202).

La importancia de este fenómeno como una forma peculiar de cultura política es destacada también por Collier (2002), quien anota que señalar a alguien como "cortacabezas", permite acabar con cualquier enemigo político. Witold Jacorzynski (2002), considera que el personaje del "cortacabezas" es símbolo de la explotación capitalista, y designa una clase especial de indígena: aquel que goza de privilegios económicos o políticos dentro de la comunidad. Al igual que Jacorzynski, Piero Gorza destaca que la lógica que guía estas narraciones pertenece a la tradición autóctona. Para Gorza (2002) "brujos y cortacabezas son figuras diferentes y no se pueden superponer, pero en el fondo pertenecen al mismo campo semántico o por lo menos utilizan el mismo repertorio de signos. Ambos son depositarios del poder y pueden usar esta prerrogativa de quitar vidas" (Gorza, 2002:176). En general, todos estos autores comparten la idea de que este tipo reciente de linchamiento está referido a la modernización de la región, a los profundos cambios culturales que ocasiona y a la forma en que esto es vivido y reelaborado en las localidades indígenas.

Centrar nuestro análisis en un linchamiento por causa de brujería nos permitirá discutir cómo el fenómeno es un producto complejo de procesos políticos y fuerzas sociales. La brujería, ha sido señalada por Carlos A. Salamanca y Florencia C. Tola:

...no es una manifestación contemporánea de la “tradición”, una superstición arcaica, ni una práctica que se supone superada por los procesos de modernización y "occidentalización" de las sociedades. Por el contrario, la brujería se constituye como narrativa del cambio, de sus contradicciones y del malestar que engendra (Salamanca y Florencia Tola, 2002: 99).

El linchamiento por brujería constituye, a nuestro parecer, no sólo una forma local de darles solución a los conflictos, como ha sido señalado por Freyermuth (2002), ni debe reducirse tampoco a una forma de resistencia social frente al capitalismo, sino que da cuenta de un saber que en sí mismo lleva intrínsecas las nociones de poder, de la importancia del individuo y la competencia; pero además, de las tensiones que está generando el creciente proceso de diferenciación social entre los tojolabales, de las paradojas e incongruencias culturales estrechamente relacionadas con los diversos proyectos sociales y económicos existentes en esta región, es decir, el de los catequistas, evangélicos, organizaciones políticas, ONG's y el del Estado. En las prácticas de brujería aparece esta tensión creciente del individuo frente a nuevos espacios y formas de competencia, entre tradición y modernidad, entre viejas y nuevas formas de prestigio y de ejercer el poder.

Para interpretar "La matazón”, como los mismos habitantes de la región la llaman, nos apoyaremos en las propias interpretaciones de algunas personalidades clave en el proceso. Esto nos permitirá acceder a los diversos discursos en pugna que tienen como trasfondo diversos y contradictorios proyectos sociales, cada uno de los cuales se pretende como el legítimo. 


\section{El caso interpretado por diversos actores sociales: una primera aproximación al hecho}

El 16 de febrero de 1998, apareció en La Jornada el siguiente título: ${ }^{6}$

Rescatan de una cueva los cadáveres de siete miembros de la UNAL, presuntamente asesinados por paramilitares priistas en octubre.

La nota relataba el rescate de siete cuerpos de indígenas pertenecientes a la Unidad Nacional Lombardista (UNAL), asesinados el 18 de octubre de 1997, en la comunidad de El Vergel, municipio de Las Margaritas, presuntamente por el grupo priista Lucha Campesina. Los cuerpos habían sido extraídos de una cueva de más de 40 metros y, según los dirigentes de la UNAL, los indígenas habían sido asesinados a balazos y luego macheteados por integrantes de Lucha Campesina, debido a diferencias políticas eideológicas. Sin embargo, el delegado del gobierno señaló que la denuncia se hizo por el robo de ganado y afirmó: "Lo que pasa es que los de la UNAL quieren lucrar políticamente con el caso para ganar más adeptos"?

Aunque los asesinatos por robo o brujería suelen ser noticia frecuente en la radio y en los periódicos locales de Chiapas y de Guatemala, varios aspectos del caso llamaron nuestra atención. Por distintas fuentes habíamos tenido información del fenómeno cuatro meses antes de que apareciera esta noticia en La Jornada. Las primeras versiones que obtuvimos aludían al robo de ganado como origen del conflicto. Fue acuerdo de la asamblea que la comunidad debía organizarse para descubrir a los responsables y matar a quienes resultaran culpables.

Se rumoraba que los ladrones de ganado podían provenir de Chanal, pero como no era posible encontrar a los responsables, empezó la sospecha de que éstos, además de abigeos tenían "poderes", es decir, eran brujos.
En la asamblea se llegó al acuerdo de buscar el apoyo de personas "vivas", de "adivinos". Se nombró a una comisión para que se encargara de localizar a estas personas en las ciudades cercanas. Para pagar por sus servicios, todos los jefes de familia cooperaron económicamente en partes iguales. En esa misma asamblea se nombraron comisiones para hacer guardia en los accesos de la comunidad e impedir la entrada y salida de cualquier persona.

Al día siguiente, la comisión integrada por tres maestros, trajo a los tres k'intanum, es decir adivinos, quienes se presentaron en la comunidad con los nombres de dos presuntos responsables: Guadalupe Méndez Méndez y José Hernández Méndez, quienes de inmediato fueron amarrados. Los hijos de ambos — cuatro del primero y uno del segundo-se interpusieron, lo que generó que también fueran sometidos y golpeados. En el momento de la detención uno de los hijos de Guadalupe Méndez logró escapar de la comunidad.

Por la tarde, los detenidos fueron sacados de la cárcel del lugar y conducidos por un grupo de 50 hombres dotados con armas de fuego y machetes hacia la cueva Petpet taj, a unos cuatro kilómetros del poblado. Al llegar a la entrada del precipicio los detenidos fueron atados a los árboles, y según como lo asentó uno de nuestros informantes, que además es cura: "Los mataron de una manera cruel, no sólo a balazos y machetazos, sino que los torturaron. Incluso ellos dicen que los abrieron estando vivos y para que no vuelvan a aparecer, esto ya revuelto con cosas de brujería, les echaron sal para que no vuelvan hacer mal, ni regresen y los arrojaron al precipicio de unos 40 metros de profundidad".

Cinco meses más tarde, dirigidos por miembros de la UNAI, la Cruz Roja y elementos policiacos rescataron los cuerpos mutilados quienes asentaron que "La causa de la muerte obedeció a fracturas de bóvedas craneana, destrucción de masa encefálica y fracturas de huesos de la cara, lesiones producidas por traumatismo craneoencefálico directo y profundo y región parcial". 
Nos sorprendió, sobre todo, el control de la propia comunidad para evitar que sus integrantes y la información sobre el asesinato salieran del lugar. La primera denuncia la realizó una de las viudas de los asesinados quien pretextando un problema con su embarazo logró salir hacia Comitán. En esta salida presentó la denuncia ante las autoridades judiciales, un mes después de los hechos. En sus testimonios, los familiares de los asesinados manifestaron las amenazas de muerte de que fueron objeto, por haber iniciado las averiguaciones.

El control fue tan fuerte que días antes del asesinato se tomó el acuerdo en la asamblea de proveer de alimentos básicos a los tendejones, pues se previó que, una vez conocidos, los culpables serían linchados y que nadie podría abandonar la comunidad. Después de la ejecución, se autorizó a una comisión para que saliera a abastecer al poblado de productos alimenticios, mientras que el portón que da acceso a la localidad se mantuvo cerrado con candado y los intentos de la policía por acceder al lugar fueron repelidos con armas de fuego por un grupo de hombres del lugar.

Según el agente del Ministerio Público de Justicia Indígena de Las Margaritas, se rescataron los cuerpos 5 meses después porque, "debido a la presencia zapatista en la zona", "no había condiciones de seguridad para realizar la fe ministerial. Para uno de los representantes de la UNAL, fue la presión pública que ejerció su organización la que incidió para que las autoridades atendieran el caso.

Por desgracia, en aquellos momentos no pudimos dedicarle la atención debida al caso por el hermetismo y la tensión que dominaba en el ambiente. No obstante, fuimos registrando testimonios provenientes de diversas personas, el primero de ellos, de una mujer vecina de El Vergel, quien actualmente trabaja como sirvienta en Comitán.

Lo que se percibía a simple vista era la falta de consenso y la diversidad de opiniones respecto al suceso: las interpretaciones variaban polarizadamente, como variaban los conceptos con los cuales se concebía la matanza: robo de ganado, brujería, envidia, ignorancia, lucha política e ideológica, pleitos entre familias, luchas interétnicas e, incluso, se dio por sentada la presencia zapatista en el lugar o, como lo publicó La Jornada, de paramilitares.

Estas interpretaciones de la matanza despertaron vivamente nuestro interés y decidimos realizar el estudio del caso, no con la intención de descubrir la veracidad de los hechos, sino de comprender el fenómeno y los diferentes niveles de conflicto que nutrieron este acontecimiento, a partir de las interpretaciones provenientes de actores que de algún modo fueron parte de este escenario.

\section{La brujería: poder y vulnerabilidad ${ }^{10}$}

El hecho de que nuestro caso de estudio esté directamente relacionado con la brujería nos permite abrir una ventana hacia esta cultura que en el texto de Lenkersdorf quedó omitida. La brujería es un lenguaje de poder que nos habla de los conflictos y de las relaciones de fuerza que se dan, en este caso, entre tojolabales. En las nociones y prácticas que la nutren encontramos viejas creencias referidas al nagualismo, pero también conceptos cristianos que en el camino se han ido reformulando, dando pie a severas resemantizaciones acordes a los cambios en las relaciones sociales que han observado los integrantes de este grupo.

Pese a que en estas concepciones referidas al álterego o a coesencias son compartidas por los grupos mayas y zoques asentados en Chiapas y de que podemos percibir en ellas un mismo estilo, existen serias variaciones de un grupo o de un poblado a otro. ${ }^{11} \mathrm{El}$ destino de esta racionalidad no ha sido el mismo en todas las comunidades indígenas, ni mucho menos en las fincas, en las actuales poblaciones rurales, o el medio urbano, como es el caso de Comitán o San Cristóbal, con una 
importante migración indígena. Algunos estudios sobre este tema dan cuenta de estas variaciones. Por mencionar algunos trabajos recientes, Pedro Pitarch (1994), Fernández Lira (1992), Pinto Durán (2002) permiten comparar el desenlace que ha tenido este sistema de conceptos en diferentes contextos Chiapanecos.

Los tojolabales no escapan a esta regla. Aquí las variaciones han tenido mucho que ver con importantes procesos históricos, entre ellos, el régimen de la finca, luego el del ejido o el de la migración dentro y fuera del país. Aunque el linchamiento por causas de brujería ha sido una práctica admitida - por no decir institucionalizada - desde tiempos muy remotos y podríamos catalogarla como un "uso y costumbre maya", consideramos que en la actualidad, esta forma de aplicación de la justicia indígena nos narra universos contemporáneos, con otros conflictos, nuevos intereses y valores reformulados. ${ }^{12}$ La cultura "funciona como síntesis de la estabilidad y el cambio, el pasado y el presente, la diacronía y la sincronía" (Sahlins 1976). Las posibilidades de significación admitidas son actos de clasificación y un acontecimiento se inserta en categorías preexistentes. Entre los tojolabales, la brujería constituye un cúmulo de conocimientos y prácticas sociales que sintetizan símbolos referidos a las creencias en las entidades anímicas relacionadas con la persona, conocidas bajo el término de nagualismo y los símbolos cristianos.

Quizá la mejor forma de comprender las nociones y prácticas de brujería entre los tojolabales es a partir de la descripción del brujo, ambiguo personaje. Entre tojolabales se designa como brujos a aquellos que echan mal, pero también a los que curan enfermedades o pueden allanar calamidades. Todo brujo es un "vivo", es decir, mi lom kristyano'uk, "no es cualquier persona", pues posee dones o poderes especiales. Como ha sido señalado por Antonio Gómez Hernández (1996), existe una fina clasificación de los "vivos" que depende tanto de sus poderes como de sus funciones. Algunos "vivos" producen enfermedad, echan mal, se "comen" a sus víctimas. De entre ellos los hay quienes pueden ocasionar males incurables y la muerte. Son los que poseen poderes más fuertes. Otros "vivos" menos poderosos sólo provocan males menores.

Pero también están los "vivos" ligados a la salud. El ajnanum, quien lee la sangre, cura con yerbas, quita y pone el mal. Según Gómez Hernández (1996), es éste el que está en la cúspide de la jerarquía de los “vivos". Le siguen el yerbero y el huesero. El pitachik' o pulsador lee la sangre y determina si el mal es gana chamel, "enfermedad provocada" o enfermedad de Dios. ${ }^{13}$

El grado de poder de los "vivos" depende de su wayjel, es decir, de su nagual. Por lo tanto existe una jerarquización que depende del wayjel. El Jaguar es, por ejemplo, uno de los wayjelmás poderosos, pero compiten con él el tlacuache que es más audaz y ágil. Eljoj o cuervo es un wayjel de brujo de los más fuertes. El joj puede curar a otros brujos heridos y también a su dueño. Cuando la gente asesina a un brujo, se le echa sal para que otros brujos que tengan por nagual al cuervo no puedan unir las partes de su cuerpo que han sido mutiladas. Otro de los wayjeles más potentes es el rayo. Éste puede ser de dos tipos: los rayos verdes, que generalmente atraen la lluvia, se considera que traen vida, resguardan los lugares sagrados como las cuevas y las semillas de frijol, calabaza o maíz entre otras; y los rojos, que pueden impedir las tempestades o destruir las milpas de los territorios ajenos. Ambos, sin embargo, son ambiguos, pues pueden ocasionar destrucción y muerte.

Por lo general el wayjelmuere con la persona, pero en algunos casos este puede ser transferido a los hijos o a la pareja. Uno de estos es la culebra, que puede alojarse en el cuerpo y en el momento que muere la persona en la cual habita, ésta sale por el ano y se mete en el cuerpo más cercano. La Ik'axib' chan o masacuata es también un wayjel poderoso. Está relacionado con los remolinos que devastan las milpas.

Se supone que todas las personas poseen wayjel, pero es frecuente considerar que son los "vivos" o brujos los 
que pueden transfigurarse. En el discurso de la gente, el wayjel aparece como malo aunque éstos estén jerarquizados y la jerarquía incluya los buenos y los maléficos. Como el personaje del "vivo", el wayjel también es ambiguo

Los "vivos" maléficos suelen ejercer sus acciones mientras sus víctimas duermen. Durante el sueño las personas suelen ser más vulnerables pues su alt ịil, algo así como "la imagen de sí mismo", suele vagar mientras duermen de día como de noche. ${ }^{14}$ Los brujos o "vivos" atrapan su altzil y se lo llevan, a veces auxiliados por otros brujos, para cocinarlo. Mientras tanto, la persona se enferma. Entonces acude con el ab'altanum o rezador, quien conoce el lenguaje para negociar con los que capturaron el atzil. Éste reza y en los rezos invoca también a santos del santoral católico.

Existe otro momento de vulnerabilidad: los primeros cuarenta días después del nacimiento. Al nacer el niño, la casa se protege con un rezador. Se hacen ofrendas para que los brujos no le hagan daño. Se llama a un pulsador para que diga qué wayjelo que dones tendrá. Si el pulsador determina que el niño será un "vivo" entonces la protección debe ser más intensa, pues corre riesgos porque los brujos lo ven ya como una competencia y tratarán de eliminarlo antes de que crezca.

Pero la inseguridad no se detiene allí. Los brujos pueden ejercer su mal fuera de estos ámbitos y suelen hacerlo con frecuencia por pugnas de poder en las que ellos mismos están involucrados o porque alguien les paga para que hagan el servicio. Estas disputas incluyen aun los actos más cotidianos. Por ejemplo, si alguien pide en matrimonio a una muchacha y la petición es negada, el altril de la pretendida puede ser capturado y ella enfermarse o morir. El "agraviado" puede acudir a un brujo para hacerle un mal a la muchacha que la marque de por vida, para que nadie se case con ella. Entre otras calamidades, el brujo puede causarle esterilidad o bien, si ésta logra tener hijos, hacer que mueran antes de la infancia.
La brujería tiene sus efectos no sólo porque el altzll sea atrapado por un wayjel, sino también por venganza. Como en el caso anterior, son frecuentes los conflictos entre los miembros de una misma familia por la forma en que es distribuida una sucesión. Si un padre deja más tierras a un hermano que a otro, esto puede generar desagravio y desembocar en un mal echado en contra del hermano favorecido por la herencia.

Con frecuencia el altzil de las personas puede ser "cazado" por envidia. Si alguien tiene más posesiones que el resto de los vecinos, sea una mejor milpa, mayor número de ganado, mejor casa u ostenta algún tipo de riqueza; los brujos pueden hacerle enfermar o causarle desgracias, bien porque ellos mismos sienten envidia o porque alguien puede pagarle para que "cace" el altril de la persona envidiada.

Paradójicamente, los “vivos", a pesar de los poderes que ostentan, son quizá los más vulnerables. También ellos pueden ser víctimas de las disputas o la envidia y viven con el riesgo permanente de ser linchados o, cuando les va bien, de que se les expulse de su localidad. Y esto incluye a los "vivos" dedicados a la salud quienes tarde o temprano se les acusa de "echar mal" y terminan sufriendo la misma suerte que los brujos maléficos. Por ello, nos decía uno de nuestros informantes, "todos los 'vivos' son brujos".

Estas concepciones, presentadas aquí en forma muy general, compiten y a veces se entrecruzan con otros ámbitos de poder. Durante la finca, por ejemplo, la brujería se inscribe dentro de las relaciones y la jerarquía sociales características de este espacio. Es decir, las formas de competencia generadas al interior de la finca fueron reinterpretadas por los peones de raigambre indígena e incluidas en la lógica de las prácticas de brujería. En los testimonios que nos presentan en Memoria Baldía, Antonio Gómez y Ruz (1992), sale a relucir la enorme conflictividad con que llegaron a vivirse tales creencias en este contexto, adaptadas a otro 
tipo de relaciones sociales, pero también a otros valores, a otras referencias empíricas, en breve, a otra ética.

Tal como hoy se presentan, las prácticas de brujería entre los tojolabales despliegan la huella de la experiencia de la finca. Experiencia todavía vigente en esta zona hasta los años cuarenta del siglo xx y que tocó su fin con la aplicación de la Reforma Agraria. ${ }^{15}$

Como ya lo señalamos en otro lugar (Pinto 2000), el finquero consideraba las prácticas de nagualismo como cosas de demonio, lo que dio más poderes a los que entre los peones indígenas se dedicaban a la sanación. A este hecho hay que agregar la estrecha relación de los finqueros con la iglesia que se concretizaba en el culto a un santo patrón y a las visitas periódicas de los curas a este universo prácticamente desaparecido en Chiapas.

Estas relaciones entre el patrón, el peón y la iglesia tuvo sus consecuencias para esta racionalidad, esta forma de pensamiento que concibe a la persona compartiendo un destino con animales o fenómenos naturales; y con el cual se interpretan la enfermedad, la muerte, el origen y la solución de los conflictos.

El cambio al régimen de ejido no forzosamente significó una reindianización como lo postuló, refiriéndose a los tojolabales, Gemma Van Der Haar (1998), si por ello estamos entendiendo un retorno al pasado. Cierto, la presencia del finquero desapareció del escenario tojolabal, pero una avalancha de mestizos con algún tipo de "misión", sustituyó su imagen paternalista: la incidencia de la diócesis de San Cristóbal en esta zona, de los catequistas y monjas, pero también, del sector salud con sus médicos y enfermeros y de ONG's ha sido de suma importancia en la región desde, por lo menos, los años setenta hasta la fecha.

Todos estos acontecimientos, más la alta conflictividad política que ha vivido la zona en los últimos años, terminaron por reconfigurar las relaciones sociales de estas poblaciones tojolabales y por ende, sus ámbitos de competencia. Pero a pesar de que los discursos de poder se han diversificado, las concepciones referidas a las almas-coesencias no han sido erradicadas. Aunque la Iglesia católica y la protestante, los maestros o los servidores del sector salud han tenido como labor la de desprestigiar estas creencias calificándolas de "brujería", dichas nociones continúan teniendo vigencia, y quizá con más fuerza, como fuente de conflictos y como discurso de poder. En los testimonios que enseguida presentamos la brujería aparece como un elemento determinante en el proceso.

\section{El caso interpretado como producto de la brujería}

Nuestro primer entrevistado fue uno de los representantes de la Organización Lucha Campesina quien ha participado activamente desde 1976 y fue catequista en comunidades de la zona desde 1968 hasta 1974.

Según este personaje, fue el robo de ganado, luego relacionado con la brujería, lo que dio origen al problema de El Vergel:

Un día estaban velando el ladrón. En vez del ladrón que se esperaba armado con rifles, vieron pasar un perro. Como creyeron que era el nagual del ladrón, la gente se organizó para matarlo, pues hay creencias. Pasó el tiempo y seguían velando al ladrón. De repente se dieron cuenta que por donde ellos estaban pasaba un zopilote... ¡Y que se pasa a cagar encima de ellos! Entonces ya no hubo duda, era un hecho que el ladrón también era brujo. Entonces con más razón: no era sólo ladrón, sino también brujo. Fue un acuerdo de la comunidad que el que cayera como ladrón dentro del ejido, tenía que pagar.

Sin duda alguna, los siete tojolabales murieron como sucede con quienes han estado acusados de brujos o han tenido algún conflicto por causas de brujería, es decir, asesinados, macheteados, las partes de su cuerpo cubiertas de sal y arrojadas a una cueva. Y es que, como ya hemos 
señalado, la brujería continúa siendo una práctica social que aparece con frecuencia en los relatos de los pobladores dela región tojolabal. Las narraciones incluyen provocación de enfermedades y muerte por "males echados", enfrentamientos y muerte por venganzas, castigo y exposición pública de los acusados, expulsión de supuestos practicantes de la brujería.

Varias localidades son identificadas como lugares donde abundan los brujos, entre otras, está el caso de los ejidos, Jotaná, Lomantán, 20 de noviembre y el k'ìis, ubicado en Las Cañadas del municipio de Las Margaritas.

Don Luis, representante de la UNAL, fue expulsado de Plan de Ayala por problemas religiosos. ${ }^{16}$ Según él, quien encabezó la expulsión fue don Rubén, un brujo. Lo hizo porque con los protestantes se le acaba el negocio, pues al cambiar de religión la gente deja de acudir a sus servicios:

\footnotetext{
El brujo o el curandero te dice: "tu papá te está echando mal, tu misma mamá te está echando mal. A veces el hijo quiere matar al papá o el papá quiere matar al hijo porque es brujo. La culpa la tiene el curandero, él dice eso para que tenga su entrada. Es que allá, al nacer un hijo dice el curandero: "que venga la velita, es que ese va a ser un rayo". ${ }^{17}$ Cuando crezca las cosas van a venir solitas. Va a traer naranja, piña, va a traer buena cosecha, va a traer todo. Por eso gasta ahorita, gasta todo lo que te piden, porque cuando este muchacho crezca, vas a ver, te va a apoyar mucho.
}

Estas concepciones están depositadas entre los miembros del grupo en forma desigual, es decir, no todos conocen estas creencias con la misma profundidad, aunque prácticamente todos temen a sus efectos:

Nosotros vamos temprano a la milpa. A veces encuentras animales extraños que no se ven, pues, en el cerro. Entonces ya decimos un wayjelal. Es un nagual, pero así como nosotros no sabemos, no podemos decir de quién será su nagual. Si será de una persona que te cuida o una persona que quiera ser malo.

Si llega un gato y se pone en frente, es el wayjel de tu enemigo. Si aparece es que ya va a ver enfermedad.

Ideas estas que van unidas a la de riesgo porque cualquiera puede ser víctima o victimario de estos poderes, a veces fuera de control, como se observa en el siguiente testimonio.

Un señor que es de González de León salió a buscar conejo, tlacuache con un rifle calibre 22. En un árbol vio dos tlacuaches. El macho se aventó desde allá arriba, se cayó y se pegó. La hembra quedó. Le dio su balazo y calló. Lo llevó a su casa y le dijo a su mujer: “pélalo y lo haces comida”. Su mujer contestó: “jay!, no sé si voy a poder, yo ya estoy mal, me salió un grano aquí, tengo un hoyo, como nacido". Y dice que es donde entró la bala a la tlacuacha.

La señora hizo la comida, pero la señora ya no comió ¡Y que a los tres días se murió la señora! Después ese señor, don Ricardo se llama, se dio cuenta que era el nagual de su mujer que se comió.

En el Vergel hay otra persona ahorita que así está. Tiene un hoyo por acá, como que pasó una bala, yo creo que le dieron un balazo a su nagual, dicen que están relacionados con un animal, sí eso dice.

Uno de los curas de la diócesis de San Cristóbal, y que conoce a fondo la región por haberse desempeñado en ella durante varias décadas, nos decía en una conversación:

Allá por los años 70's en El Vergel hubieron muertes por cuestiones de brujería, del k'uxwanum, "el que come". Esto era común entre los tojolabales. En una ocasión durante la fiesta de Santa Bárbara allá en Bajucú, hubo carreras de caballos, de cinta, pues, de gallo viejo para cortarle la cabeza. Entonces uno de los corredores 
se cayó y se murió. Por su puesto, todos corrían tomados. Le echaron la culpa de ser el k'uxwanum a un niño de tres meses y lo mataron en la comunidad.

Los testimonios anteriores son sólo una muestra de la relevancia del fenómeno para la vida social de los tojolabales. No todos tienen el mismo número de wayjel, y cada wayjelal posee diferentes poderes que pueden ser utilizados a favor o en detrimento de los otros. Bajo este principio, los brujos poseen wayjel poderosos para curar, pero también para infligir daños, traducidos en enfermedad, muerte o calamidades. De este modo, el poder se encuentra distribuido desigualmente. Una desigualdad que toca el fondo de las relaciones y crea una tensión permanente que atraviesa todo el tejido social.

Aunque muchos de nuestros entrevistados dicen ya no recurrir a los servicios de los curanderos o brujos, podemos percibir que cuando se refieren al pasado o a personas no evangélicas, dichas concepciones siguen vivas. ${ }^{18}$

Sólo por la fuerza de estas concepciones se puede comprender que durante el proceso se hayan utilizado para legitimar el linchamiento. Pues como veremos en las entrevistas que siguen, hubo un uso interesado de estos significados para resolver conflictos entre familias y querellas entre organizaciones campesinas. Sin embargo, estas concepciones compiten con otros discursos que ofrecen otra interpretación de la realidad y que intentan imponerse o legitimarse como los verdaderos. Sería el caso, por ejemplo, del discurso político proveniente de las organizaciones campesinas, el de la Iglesia católica, el de la evangélica, o el de los maestros.

Estos discursos asocian estas nociones a un pasado "atrasado", y dan por hecho que caducaron con la llegada de la palabra de Dios, de catequistas y monjas y de los promotores de salud quienes ofrecieron otras explicaciones a los procesos de salud-enfermedad, así como a sus alternativas de atención. Se ha generado así un discurso de desprestigio respecto de estas creencias.
Un discurso a la luz del cual se juzgan estas prácticas y concepciones como producto de la ignorancia.

\section{La ignorancia como relato}

\begin{abstract}
"Toda la comunidad es católica y por lo mismo siempre tenemos arraigadas algunas costumbres, entre ellas, las de creer en adivinos o brujos". 19
\end{abstract}

La brujería es una práctica recurrente aun para los que niegan estas creencias y que por su propia posición social están obligados a concebirla como un hecho irracional, nos referimos a los maestros, catequistas, pastores evangélicos, líderes políticos, promotores de salud. Existe entonces un discurso que niega la validez de este conocimiento considerado como producto de la ignorancia y la falta de educación, pero al cual, no deja de temérsele.

Este discurso sobre la ignorancia tiene también que ver con la presencia de la Iglesia católica en la región:

\footnotetext{
Muchas comunidades todavía están muy atrasadas, la gente está muy creída. Posiblemente haya gente muy fuerte, muy valiente, que tiene sus signos muy fuertes. Yo conozco un señor así, pero no por eso podemos creer en esas cosas. Aquí en el ejido así es, y también para muchas comunidades. Lo único que ha resuelto los problemas de esas creencias es la catequesis. Cuando no había catequesis era cada dos días la matanza. Delante de Napité, ¡qué bárbaro!, caían dos o tres en el mes. Hace años mataron a una señora a balazos porque era bruja. Llevaba al niño cargando y también a él lo mataron.
}

Sin embargo, estas categorías no dejan de ser usadas aun por los propios catequistas y maestros como estrategia en la resolución de este conflicto: 
"pues yo pienso que la gente que planeó hacer eso fue por vil ignorancia", nos comentó uno de los dirigentes de Lucha Campesina. "Es como regresar al pasado muy atrasado. Los mismos trabajadores de la catequesis fueron los ejecutores de este caso. Entonces es un trabajo muy sucio, muy atrasado, mucha ignorancia. No debería haber creencias de la brujería pues ya ha habido trabajo con la gente de El Vergel. Yo hago responsables a los catequistas, porque ellos no hicieron trabajo, al contrario fueron cómplices de todo esto.

La "religión tradicional", como ellos mismos la nombran, es una síntesis de categorías culturales. La noción de brujería no puede entenderse si no hacemos referencia a las creencias en el nagualismo y asociación al mal de origen cristiano. Es decir, en los propios testimonios es posible percibir cómo las creencias y las prácticas de brujería se asocian al hecho mismo de ser católicos. Y a pesar de que se esperaba que con la catequesis se eliminarían los conflictos originados por estas prácticas, al parecer, al satanizarlas se les dio más fuerza. Un cura nos comentaba al respecto:

Tu puedes hablarles de Jesucristo mil años, sobre el hijo de Dios y que la fregada y todo, y no te lo van a entender. Los tojolabales interpretan la palabra de Dios. Ellos lo entienden en el sentido que todo tiene vida. Creen que la enfermedad viene porque estas perdiendo la vida el corazón, porque hay la intervención de otro que se lo está “comiendo", porque está el pukuj que son realmente los tigres malos. Eso es la mentalidad maya. Sucede que si te está acabando la vida alguien que no te lleva bien, el mal se cura acabando con el otro.

Este discurso sobre la brujería como ignorancia es recurrente también como estrategia entre los médicos locales para desprestigiarse mutuamente entre su clientela.
En este sentido se expresó una partera originaria de San Cristóbal que vivió en El Vergel durante 15 años.

Yo les quité mucho de esas creencias; que si es brujería, que si tal. Me llevaban enfermos de unas colonias muy lejanas hasta por Altamirano. De un lugar que se llama Chibtic diez hombres me llevaron un enfermo que era tojolabalero. También llevaban a otro muchacho amarrado. Les dije: "qué barbaridad, no son hijos de Dios ustedes, pobre muchacho". Le di una medicina al enfermo y vomitó dos o tres veces. Con la gracia de Dios, yo lo curo con yerbas, ruda, hierba buena, epazote y un poco de alcanfor y alcohol y agua curativa y ya con eso. Y sí se compuso, pero les dije al otro día que amaneció: "por qué tienen amarrado a ese... no es brujo, los brujos son las lombrices". Si lo matan yo mismo voy hacer un papel para Margaritas... porque no es brujo es mentira... así lo controlé a muchísima gente.

Ah, que porque si ven pasar un animal, si pasa silbando, si oyen que llora en la noche, si gritan los gatos, un montón de boberas piensan esas gentes.

Se trata de una forma de poder estigmatizada y si se quiere, hasta desprestigiada, pero no por ello, sin fuerza. El propio líder entrevistado deja entrever su creencia en estas categorías, y hasta los mismos maestros-catequistas fueron impulsores en resolver el conflicto haciendo uso de dichos conceptos. Conceptos que por regla tienen un antecedente relacionado con la envidia.

La envidia es tan importante para relaciones sociales de este grupo que merece por sí sola un subrayado.

\section{Kux k'ujol: La envidia como competencia}

La envidia en el contexto de las creencias indígenas ha sido señalada en los trabajos de corte funcionalista como un mecanismo de control social. Por lo general, los señalamientos teóricos que se han hecho sobre la envidia 
constituyen más bien notas sueltas. Por lo que hemos percibido en el trabajo de campo, es necesario comprender esta emoción en el marco de las categorías culturales del grupo y como parte de un tramado de las emociones determinadas por estas categorías. No es posible entender la envidia si no se comprende por ejemplo, el miedo, la venganza, la amenaza, la ofensa, el odio. Las emociones no son meros impulsos o disposiciones naturales e individuales, son fruto de elaboraciones culturales. Es decir, la acción y la emoción están influidas por la manera de interpretar el mundo. Un mismo acontecimiento, la muerte, por ejemplo, puede dar origen a diferentes emociones, dependiendo de cómo a ésta se le interprete.

Una de las formas de nombrar la envidia en tojolabal es k’ux k’ujol, es decir, "corazón sucio" o "remolerse el corazón”. Más que un mecanismo de control social, en este caso la envidia constituye una estrategia en las relaciones de fuerza, una forma de competencia.

Líneas más arriba señalamos cómo en las propias nociones de brujería se encuentran contenidas formas de competencia, entre las cuales sobresale la envidia. Con la diversificación social, estas formas de competitividad han variado y crecido. La adscripción de una importante población masculina en el ejército, la migración de algunos hombres de esta localidad hacia otras partes fuera o dentro del país, pero también de algunas mujeres que salen del lugar para emplearse en el servicio doméstico en ciudades como Comitán o Las Margaritas ha significado que una parte de la población tiene acceso a mayores recursos que se traducen en mejores casas, mejores y a veces distintas vestimentas, mayor número de ganado; o en la adquisición de objetos como automóviles, televisores, tocacintas, por mencionar algunos. La envidia, por lo tanto, también se ha multiplicado con sus consecuentes variaciones:

"Esa gente que fue ejecutada, nunca los vi borrachos, no eran malos hombres ni tenían mala conducta. Son gentes muy buenas. El problema es creo, que ya es envidia, egoísmo", afirmó don Feliciano.

La envidia fue una causa señalada también como inicio del conflicto, por el representante de la UNAL quien nos confirmó:

Lo que ocurrió en El Vergel es que las gentes que fallecieron eran trabajadoras. En los tiempos de empezar a preparar la tierra y sembrar, ellos le echaban ganas. Después de terminar el trabajo se iban a la ciudad de México a buscar trabajo de albañilería, en obras. Como ellos no tomaban trago, lo que ganaban lo invertían en unas cositas, animales, tenían su casita de tabla pintadita. Pero un grupo de cuatro maestros, mientras ellos lo que cobraban quincenalmente lo agarran para vicios y no prosperaban, le echaron la culpa a esos señores que murieron de que ellos son los que venden los ganados, pero es totalmente falso. Por envidia, más que nada. Ellos empezaron a decir: ¿de dónde sacan dinero para sus casas bien hechas?, de seguro ellos lo están robando el ganado.

Es decir, existía una dificultad evidente entre los acusados y los maestros, líderes de la matanza:

Y es que había dificultades entre don José y el maestro Trinidad. Es que Trinidad era muy alzado. En la calle les gritaba a don José y sus hijos, que eran unos alzados, que esto y aquello. Cuando tomaba, también hacía disparos al aire. Entonces había choque, por esa razón los acusaron. Los responsables de la matanza son tres maestros de la comunidad, que forman parte de los catequistas: Trinidad Jiménez, Enrique Méndez López y Mario de Jesús Gómez Méndez. Dos andan sueltos. Ahí viven en El Vergel, ahí están paseándose. Son un grupo de gente, mas no toda la comunidad, sino un grupo de gentes.

El profesor Trinidad Jiménez, quien ahorita está en la cárcel, junto con otros, contrataron unos brujos. Y 
resulta que el domingo 18 de octubre de 1997 , invitaron a la comunidad a los brujos, curanderos para que señalaran los culpables. La comunidad no estaba de acuerdo en que eran las dos personas señaladas los ladrones. Pero ya tenían armada la cosa que iban a hacer esos señores, cuando llegaron señalaron a dos padres de familia, pero el encargado de dirigir todas esas acciones fue el profesor Trinidad Jiménez y Mario y otros dos más. Lo único que sabemos por otras gentes es que ellos hicieron el acuerdo antes, porque al llegar a El Vergel, los brujos directamente señalaron a los responsables de las pérdidas de ganado: don José Hernández y Guadalupe Méndez. Inmediatamente amarraron a las personas señaladas, pero también a sus hijos. Uno de los hijos del difunto José, se llama Javier, logró escaparse, pero al correr le llegaron dos ráfagas de balazos, de los rifles de 16 tiros. A pesar de las súplicas de las mujeres, unas 50 gentes llevaron a sus maridos a una montaña, a unos 4 kilómetros de la comunidad. Pero los llevaron amarrados, sin darles tiempo a que hablen con sus familiares, con sus hijos. Se dirigieron a la cueva, como a las cinco de la tarde. Yo creo que ya lo tenían buscado este lugar porque era una cueva muy peligrosa. Los amarraron en un arbolito que está cerca de la cueva y les echaron balazos, les cortaron la cabeza, los destrozaron, les echaron sal y ahí los tiraron como el perro.

Pero la envidia, en este contexto, es una emoción que se configura a partir de las concepciones generales del grupo, de las prácticas de brujería. Envidiar o ser sujeto de envidia puede acarrear toda clase de calamidades, entre ellas la enfermedad o la muerte:

La envidia es lo que más gobierna. Es que las personas de las comunidades indígenas no te pueden ver comprar un burrito, no te pueden ver comprar alguna cosa. Luego empieza la enfermedad y se va a consultar con un brujo. Entonces el brujo dice: ¿Por qué compraste pues animales y hay gente con más edad y no tiene nada? ¿Y tú ya querés tener?, entonces así no. Vamos a hacer una promesa. Vamos a ir a ver tu casa. Busca flores, busca sapos. Entonces uno cree y el curandero es lo que quiere, pues, que tenga negocio. La envidia es el coraje, de por sí. Si alguna persona tiene buena milpa, cortan el alambre y lo dejan entrar el ganado para que lo acabe.

Si seguimos la lógica de reflexión de Carlos Lenkersdorf, el fenómeno social de la envidia podría interpretarse en este caso como un corrector del sistema de igualdad. De hecho, en los trabajos antropológicos de corte funcionalista sobre este tema en Chiapas, la brujería y la envidia son considerados como mecanismos de control social, que trabajan para asegurar un reparto igualitario de los bienes. Lo que nos dicen los testimonios hasta aquí expuestos es que en las propias concepciones de brujería están implícitas formas de poder y de lucha: envidiar es competir. Lo que ha variado es que se han introducido motivos nuevos de envidia, pero ésta sigue siendo admitida culturalmente como modo de competencia. Una competencia que se extiende hacia ese mundo paralelo en el que las almas suelen ser "raptadas" o "comidas" por wayjeles más poderosos, y que puede repercutir en este mundo en forma de infortunios, enfermedad o muerte.

La forma que toma la envidia en estos contextos es indicador de una importante paradoja cultural: con la envidia se señala a aquellos que tienen más, pero en la propia emoción va implícito el deseo de también poseer.

\section{Intereses y filiaciones políticas como explicación del conflicto}

Además de las nociones y prácticas de brujería en la configuración del conflicto que estamos analizando, el problema no puede entenderse si no se revisan categorías y acciones que competen a las organizaciones y a las 
formas de autoridad local como recursos de mediación política.

En el ambiente político de estas comunidades ha dominado la presencia de diversas organizaciones campesinas y partidos políticos, de agentes de la diócesis de San Cristóbal y de otras asociaciones religiosas. Por lo general, las comunidades son identificadas en la región por su filiación a alguna organización política y religiosa: priistas, perredistas, zapatistas, católicos o evangélicos.

La organización que mayor presencia ha tenido en la región es La Unión Lucha Campesina - filial de la CNC y del PRI-. Ésta alcanzó a tener influencia en 20 comunidades y el control del transporte que comunica los ejidos con las cabeceras municipales. Disputas internas al interior de Lucha Campesina separaron en 1985 a las nueve comunidades que crearon Pueblos Tojobales, filial del PSUM primero, y después del PRD y la CIOAC. En los años recientes han aparecido nuevas organizaciones, entre las cuales se incluye La UNAL. A pesar de que muchas de las comunidades se encuentran fragmentadas política y religiosamente, resulta prácticamente una obligación para los pobladores de la región adscribirse a alguna de las organizaciones, pues éstas constituyen un recurso de mediación ante las instancias gubernamentales.

Al interior de las comunidades, la vida pública está regida por los "acuerdos" que alcanzan los hombres durante las asambleas comunitarias. Las resoluciones de la comunidad o de la "gente" como regularmente se le denomina a un acuerdo colectivo sobre conflictos diversos, representan la instancia de mayor autoridad en el ámbito local. En las comunidades en las que coexisten distintas filiaciones políticas y religiosas, se llevan a cabo otro tipo de asambleas, pero la ejidal sigue siendo la que congrega a la mayoría de los jefes de familia. Refiriéndose a la asamblea en un poblado tojolabal, José Luis Escalona Victoria (2000) ha observado:

...las decisiones tomadas o las soluciones encontradas pueden resultar de una competencia entre personas y grupos con capacidades diferenciadas. Por un lado, muchas de esas diferencias tienen que ver con distinciones previsibles de autoridad para hablar y decidir, como la que podría existir entre los que son considerados autoridades frente a los que no tienen reconocimiento como tales, o de la diferenciación entre los "vivos" y "no vivos", o la diferencia entre los adultos a los más jóvenes, o de los hombres frente a las mujeres. Por otra parte, esa diferente capacidad de incidir en las decisiones puede también resultar de distintas capacidades de movilizar apoyo a favor de una u otra posición, basadas en lealtades personales, en compromisos de reciprocidad e incluso en habilidades argumentativas (Escalona, 2000: 192-193).

La intolerancia política y religiosa en el interior de las comunidades ha sido una práctica bastante común durante las disputas internas y contra quienes intentan cambiar de partido o religión. Un caso extremo del uso de la fuerza física y de violencia colectiva es la resolución de asamblea de algunas comunidades de expulsar a quienes tratan de cambiar de adscripción religiosa. Aunque los lideres de organizaciones y autoridades ejidales, sostienen que en sus respectivas comunidades existe libertad de asociación política y religiosa, también reconocen que, quien haya elegido una religión o partido distinto al de la comunidad, tiene la obligación de dar parte a las autoridades locales para que ellas mismas se encarguen de "trasladar sus pertenencias" a un lugar fuera de la comunidad en el que el disidente haya encontrando manera para mudarse a vivir.

Mediante un discurso que legitima la autoridad de la asamblea como la instancia que vela por el bienestar de la comunidad, los grupos de poder del interior de las comunidades (maestros, ancianos, dirigentes de organizaciones), se erigen como una voz autorizada para "defender" los intereses de la colectividad, pero también para inculpar a los disidentes, al margen de toda lógica de la racionalidad del sistema legal positivo. En muchos de los casos de violencia sobre los miembros de las 
mismas comunidades hay una ausencia permanente del Estado. Por eso pensamos que la noción de "acuerdo de la asamblea", de comunidad igualitaria, consenso y armonía social, debe ser revisada y cuestionada por quienes se interesan por comprender la compleja realidad al interior de estos grupos sociales.

En la interpretación sobre la muerte de los siete campesinos de El Vergel aparecen estas luchas políticas como trasfondo. Luchas que nos ubican en un contexto actual en el que una pequeña comunidad es partícipe de la problemática regional, pero además incompresible si no se le sitúa en un marco sociopolítico más amplio. Las interpretaciones de uno de nuestros informantes ayudan a comprender la complejidad de las luchas políticas en la región.

José Hernández, el asesinado, era uno de los fundadores de Lucha Campesina. El pleito comenzó allá por los años setentas cuando murió uno de sus familiares. Pero éste también mató a gente de los Méndez. Se fueron calmando las cosas. Yo recuerdo que José Hernández era uno de los luchadores de ahí, junto con otros dirigentes y otras comunidades fundaron Lucha Campesina. Entonces los Méndez no apoyaban a la casa ejidal. Sucede que muchos conflictos actuales entre tojolabales vienen desde atrás y, como llegó la palabra de Dios, las comunidades llegaron al acuerdo de que ya nadie puede matar. En este caso ya no hubo oportunidad de venganza.

Yo así lo he visto, si fulano de tal que es mi enemigo porque en aquel tiempo hizo algo en contra de mí, es que es PRD o EZLN, entonces yo voy a ser del PRI, la cuestión es acomodarse, porque me la debes y tarde o temprano me la vas a pagar.

Un evento que ilustra las confrontaciones violentas entre organizaciones campesinas de la región es el asesinato de dos miembros de Lucha Campesina en el ejido Veinte de Noviembre en 1981, ejecutados por disidencia política con el respaldo de la comunidad. Uno de los representantes de esta organización narró los hechos:

Entonces los compañeros de los que fueron muertos por parte de la Unión, pidieron nuestro apoyo. Recuerdo que fuimos como unos tres mil cabrones ahí en la comunidad de Veinte de Noviembre. Acordamos, con el juez municipal, aunque él no quería entrar, neutralizar las fuerzas para que no hubiera más muertos, pero ya no se podía porque la gente ya lo tenía resuelto. Nos querían joder a nosotros porque estábamos apoyando a la otra parte.

Nos metimos a Veinte de Noviembre de buena manera, para platicar con la gente y entender qué pasó, por qué estaban tirados los compañeros ahí, comiéndolos los cuches. Eran ciento diez o ciento quince hombres armados que nos estaban esperando, no queríamos matar, sólo entrar a negociar, platicar y si el amigo que mató está ahí, entonces sí lo matamos. Nos metimos, pero divididos todos los que traían armas largas entraban por los lados del ejido. Eran como tres mil, me acuerdo que se juntaron no sé cuantas armas esa vez y nos metimos. Entonces los que llevaban armas cortas también se juntaron y los que no llevaban nada, también. Y cuando vieron que nosotros llegamos a la orilla del ejido empezó la balacera. No hubo muertos, puros heridos. No nos dejaban acercarnos a los cuerpos de las personas que habían matado.

El problema era de que ellos no querían que la gente estuviera con nosotros en la Unión porque el líder de la CNC decía que nuestra organización era guerrillera. Fue el santo remedio de que no hubiera más muertos. Entonces entramos a la casa donde estaban tirados los muertos. Y también fuimos a ver la casa de los que debían esos muertos, también estaban heridos. Como la gente es muy curiosa empezó a revisar la casa, se metieron al sitio, se miraba sangre. 
Pero seguramente dicen que este hijo de la chingada, dicen, que mató a mi cuñado por hay está escondido...allá estaba escondido allá adentro; que lo van encontrando pues, estaba el juez. Delante del juez lo estaban despedazando, yo no podía también decirles: "dejen eso", porque son duros. Del muerto brincaban los pedazos de carne todavía así, y el juez dijo: vámonos, vámonos.

Lo he vivido eso y lo he visto, pero fue la medicina para resolver el problema.

El uso de la violencia como recurso en las luchas de las organizaciones políticas es una práctica cada vez más recurrente en las comunidades de esta región. En la prensa local es fácil encontrar notas que describen hechos violentos entre grupos políticos confrontados. Por señalar un hecho reciente en esta zona, está como ejemplo, el secuestro de militantes de la CIOAC por miembros de una fracción de esta misma organización, ocurrido entre los meses de septiembre y octubre de 2003.

Los nexos políticos entre dirigentes y funcionarios de gobierno fueron señalados por uno de los dirigentes de la UNAL para explicar la lentitud de las autoridades en atender el caso.

Aunque las autoridades dieron la orden a la fuerza pública para que se trasladaran a El Vergel y dieran fe ministerial, nunca lo hicieron. El delegado de gobierno, apoyaba a esa gente porque eran de la Unión Lucha Campesina. Como ellos no actuaban, nos organizamos y el 14 de febrero de 1998, nos trasladamos a la cueva junto con la policía de Seguridad Pública y la Cruz Roja, así se logró rescatar las osamentas.

Cuando detuvieron al maestro Trinidad, la comunidad El Vergel se dividió. Primero eran todos de la Unión campesina, pero para tener fuerza se pasaron a otra organización que es la CIOAC. Pero resulta que el dirigente, Pancho Gordillo, formó otra organización que es la de Pueblos Mayas tojolabal. Él es quien empezó a buscar la libertad del maestro Trinidad.

Como hemos podido ver, en las historias de estas confrontaciones se entretejen venganzas personales y disputas colectivas de larga duración, la acción política de instituciones y agentes del Estado. Cada historia de violencia colectiva, en este caso el linchamiento por brujería, revela un momento de incertidumbre social, como si se tratara de un estado de excepción en el que la imagen de la autoridad y el ejercicio del poder se volvieran difusos o adquirieran muchos rostros.

\section{Una última interpretación a manera de conclusión}

Por lo general, se ha vuelto un hábito comenzar los estudios sobre los tojolabales por su definición. Los "legítimos hombres", concluimos, son verdaderos hombres y no utopía. Las interpretaciones sobre el caso de linchamiento por brujería que venimos de presentar ponen en entredicholaidea de una comunidad coherente, homogénea y armónica. La visión que queda es la de una sociedad ambigua y fragmentada. Como ha sido señalado por Miguel Lisbona Guillén (2003) a esta fragmentación han contribuido en gran medida los diversos modelos de sociedad que atraviesan las poblaciones tojolabales. Proyectos muchas veces en pugna, que luchan por legitimarse: el modelo del Estado con sus programas educativos y de salud, el modelo católico confrontado con el evangélico o el modelo de las organizaciones y actores políticos, tan prolíferos en la región.

Esta diversificación no ha logrado erradicar la brujería. Por el contrario, en sus concepciones y prácticas se concretizan valores en pugna, principios culturales contradictorios como son la colectividad y el individuo, la tradición y la modernidad, la igualdad y la diferencia. 
La brujería continúa siendo un referente importante del imaginario cultural y la cultura política local, pero ésta no constituye la única forma de ejercer el poder. Con la revisión de un caso de linchamiento hemos querido mostrar cómo viejas concepciones culturales, como el nagualismo, han sufrido innovaciones para hacerlas operantes en un contexto complejo donde son usadas como discursos paralelos y a veces traslapados a los de los agentes de la iglesia, los partidos políticos, los maestros, entre otros. Discursos a los cuales se recurre como estrategias en las relaciones de fuerza, en la resolución de conflictos, en la configuración de las relaciones de poder.

La experiencia social y política tojolabal rebasa ampliamente el ámbito comunitario. Desde los inicios del problema que dio origen al linchamiento es posible percatarse de que su instancia mayor: la asamblea, quedó rebasada. Los entrevistados aluden al hecho de que en varias ocasiones se recurrió a las autoridades judiciales para poner fin al robo del ganado. Ante la nula respuesta, decidieron resolver el problema en el contexto de la asamblea. La comunidad se cerró, esta vez en un sentido más que metafórico, pero la envergadura del conflicto fue tal, que se recurrió a una organización política regional, la UNAL, quien fungió como mediadora entre los familiares de las víctimas y las autoridades judiciales.

En la asamblea donde se tomó el acuerdo de linchar a los acusados de ladrones de ganado y brujos no estaban presentes las mujeres. Cuando se designó a los dos culpables, sus hijos salieron a la defensa y su desacuerdo fue acallado con el peor de los silencios. Cinco personas fueron linchadas por no estar de acuerdo con la resolución de la asamblea. Un acuerdo que no sólo "resolvía" el problema del robo de ganado, sino querellas entre familias, organizaciones políticas y hasta la envidia quelos dos inculpados habían generado entre sus vecinos, por gozar de diferentes condiciones de vida. ¿De qué tipo de consenso e igualdad estamos hablando?

A primera vista, el linchamiento podría explicarse por el fracaso de ciertas instituciones para imponerse, $y$ no nos referimos exclusivamente a la autoridad policiaca, pues en ciertos contextos, como en El Vergel, tampoco las diversas instituciones religiosas que allíse encuentran instituidas han logrado erradicar la brujería y los linchamientos por estas causas, que en espacios como éstos constituyen una práctica cultural admitida y reformulada frente a los nuevos contextos. El Estado, la ley positiva, el ejercicio de la ciudadanía se encuentran supeditados a los "acuerdos colectivos" tomados, por lo general, en las asambleas comunales, instancia donde se ventilan los problemas que atañen a la colectividad. Una colectividad cada vez más diferenciada, en cuyo seno confluye un complejo de fuerzas e intereses personales.

$\mathrm{El}$ análisis de un acuerdo tomado en asamblea comunitaria, nos pone ante una cultura en permanente construcción. Entendida la cultura como proceso nos enfrenta ante la inoperatividad teórica de conceptos como tradición, costumbre, raigambre indígena, herencia social. No es fácil renunciar a las ideas de lo "indígena" como una coherencia, una pureza étnica aislada del resto de la sociedad y que nos remite un pasado mítico. Pero es necesario pensar a los grupos sociales en su temporalidad, partícipes de procesos más amplios que traspasan los ámbitos locales.

A pesar de que este linchamiento es un caso extremo de violencia y de que no constituye de ninguna manera una constante al interior de este grupo, el presente estudio nos ha confrontado ante el drama de la violencia y de la muerte entre personas. Imposible soslayar la importancia de este hecho. Tema que dejamos abierto para un imprescindible debate posterior.

\section{Notas}

${ }^{1}$ No es nuestra intención retomar esta discusión lingüística. Para mayores detalles, revisar: Lenkersdorf, Carlos (1996), Los hombres Verdaderos. Voces y testimonios tojolabales, Caps. I y II, Siglo xIX, México. 
${ }^{2}$ El Vergel es un pequeño poblado de unos mil doscientos habitantes. El régimen de propiedad es ejidal y forma parte del municipio de Las Margaritas, Chiapas. Situado en sus límites con los municipios de Chanal, Comitán y Altamirano, el poblado se encuentra dentro de una zona de transición lingüística, geográfica, política y cultural, donde confluyen las lenguas tojolabal, tseltal y el castellano: las regiones de Los Altos de Chiapas, los Llanos de Comitán y la región Selva. La zona es también frontera que limita el área de influencia del EZLN.

Esta microrregión es conocida por sus pobladores como la Cañada Tojolabal y está asentada en lo que fueron tierras de antiguas fincas, de ahí que cada comunidad conserva el nombre de la finca sobre la cual se fundó. Los pobladores de esta región se distinguen del resto de este grupo lingüístico por conservar el idioma y la 'ropa típica'.

El grupo lingüístico tojolabal es uno de los nueve grupos étnicos que habla una lengua indígena en el estado de Chiapas. Los tojolabales residen en poblados dispersos de seis municipios fronterizos con Guatemala (Basauri 1998 [1931], Lenkersdorf 1996 y Ruz 1990 [1983]). Se estima entre 50 mil y 80 mil el número de hablantes de esta lengua (Lenkersdof 1995, Gómez 1997). Parte de esta población vive en algunos barrios de la periferia de Comitán y de Las Margaritas. Después de levantamiento zapatista ha aumentado el número de indígenas tojolabales residentes en estas ciudades.

${ }^{3}$ Como por ejemplo el linchamiento de asaltantes-violadores que se dio en La Hormiga, una de las colonias de San Cristóbal de Las Casas con población principalmente indígena. Al parecer esto tuvo que ver con el caso de una turista japonesa asesinada, alrededor de 1999.

${ }^{4}$ En zonas urbanas son frecuentes los de linchamientos por delincuencia. En un poblado del estado de Morelos, por ejemplo, se dio recientemente un caso en el que un abigeo fue ahorcado. En la Ciudad de México, son frecuentes los linchamientos de delincuentes en los microbuses. Tenemos noticias de un caso en Santa María Magdalena Petlacalco, Tlalplan, donde fue linchado Carlos Pacheco Beltrán, durante las festividades religiosas, en junio del 2001. Los casos más impactantes y numerosos son los de Guatemala, generalmente también contra delincuentes, pero algunos derivados de conflictos políticos intracomunitarios en contextos de los efectos del conflicto armado que ahí se vivió. La mayor parte de los casos se registraron en zonas indígenas, en la región oriental, el Petén que colinda con Chiapas. La Misión de Verificación de las Naciones Unidas en Guatemala ha registrado 300 casos de linchamiento desde 1996.

${ }^{5}$ Estas historias son recientes en el imaginario social y se dan preferentemente en el medio rural. Los "corta cabezas" pueden ser mestizos o indios, según los relatos, y su función es atrapar a sus víctimas, por lo general indígenas, y cortarles la cabeza para fortalecer los puentes y carreteras de reciente construcción. Por lo general, los acusados de ser 'corta cabezas' suelen ser linchados de la misma manera que los acusados de ejercer la brujería. Aunque los trabajos etnográficos han dado cuenta de estas historias en el contexto rural, es frecuente escucharlos también en la ciudad. En San Cristóbal de las casas, un taxista nos decía: "hay que cuidar mucho a los niños porque los 'corta cabezas' cada vez roban más niños para hacer los puentes" ${ }^{6}$ Ver sobre el mismo evento, diario Cuarto Poder del 13 diciembre de 1997, editado en Tuxtla Gutiérrez, Chiapas.

${ }^{7}$ Al parecer, como organización la UNAL no sobresalía en la lista de organizaciones regionales y sólo cobró cierta presencia a partir de su intervención en este caso.

${ }^{8}$ Se dice que la sal impide la unión de las partes del cuerpo y, por tanto, la resurrección aun de los que tienen el waygel más audaz, más astuto, ideas que discutiremos más adelante.

${ }^{9} \mathrm{El}$ Vergel, localidad en que se dieron los hechos que venimos describiendo, ha sido de filiación priista y no ha tenido una participación, por lo menos abierta, con el EZLN.

${ }^{10}$ Con la gentileza que le caracteriza, Antonio Gómez Hernández nos prestó su valiosa aportación para este apartado del trabajo. ${ }^{11}$ Existe una amplia literatura que da cuenta de estas concepciones: Calixta Guiteras H. (1961), Villa Rojas (1963), Roberta Montagú (1970), Esther Hermite (1970), Norman D. Thomas (1974), Ulrich Köhler (1977), Pedro Pitarch Ramón (1996).

${ }^{12}$ En Muerte por Sortilegio: brujería, nagualismo y reciprocidad negativa en una finca de Los Altos de Chiapas (2002), Astrid Pinto discute cómo el linchamiento por causas de brujería o nagualismo admitido culturalmente en las comunidades, en la finca se convierte en una práctica que refleja las reformulaciones simbólicas que van a la par de las relaciones sociales patrón-peón. Las ideas referidas a las coesencias (nagualismo) constituyen en sí mismas un lenguaje de poder: Un lenguaje reformulado para hacerlo operativo en las relaciones sociales que se dan en el contexto de la finca, y que por el mismo contacto con los patrones y los símbolos cristianos se convierte en "brujería". 
${ }^{13}$ Para mayores detalles de esta clasificación ver Gómez Hernández, Antonio (1996).

${ }^{14} \mathrm{El}$ altril puede traducirse literalmente como corazón, refiriéndose al órgano, pero también tiene el sentido de "imagen de sí mismo".

${ }^{15}$ Es importante señalar que la formación de las comunidades tojolabales es reciente, pues éstas se originaron a partir de la Reforma Agraria, en contraste con las comunidades de Los Altos de Chiapas que fueron pueblos tributarios de origen colonial (Escalona, 2000:184).

${ }^{16}$ Plan de Ayala era anteriormente la finca Jotaná.

${ }^{17}$ Ser rayo significa que se tendrá un Wayjel poderoso para hacer el bien o el mal, como expusimos más arriba.

${ }^{18} \mathrm{Al}$ respecto, Carlos Fernández Liria sentó un precedente importante al interpretar la adopción de un nuevo credo por parte de tzotziles asentados en la periferia de San Cristóbal. Su artículo "Enfermedad, familia y costumbre en el periférico de San Cristóbal" (1992), es un original intento por mostrar que el fenómeno de conversión puede obedecer a profundas causas culturales. En el caso que estudió, constituye un intento de crear un nuevo espacio social en el que la sociabilidad sea posible sin los conflictos que ocasiona la envidia, la brujería, el miedo a la enfermedad. Su tesis es que la conversión, en este caso particular, no implica una ruptura total de los viejos esquemas interpretativos, pues la mentalidad indígena no queda en el pasado, sino que encuentran en la palabra de Dios, fuerzas protectoras más poderosas, contra el perpetuo peligro en que, por sus propias concepciones, vive el indígena.

${ }^{19}$ Declaración de una de las viudas ante el Agente del Ministerio Público.

\section{Bibliografía}

Bourdieu, Pierre, 1994, Raisons practiques. Sur la théorie de la action. Seuil. Paris.

Basauri, Carlos, 1998, [1931], Tojolabales, treltales y mayas. Breves apuntes sobre Antropología, Etnografía y Lingüistica, Colección Facsímil, uniCACH, México.

Collier, Jane F., 2000, "La solución pacífica de un caso de "cortacabezas" en Zinacantán” en Witold Jacorzynski (coordinador): Estudios sobre la violencia. Teoría y práctica. CIESAS, México.
Escalona Victoria, J. L. (2000), "Comunidad: jerarquía y competencia. Examen a través de un pueblo contemporáneo" en Anuario de Estudios Indígenas VII, IEI- UNICACH, México.

Gómez Hernández, Antonio y Mario H. Ruz, 1992, Memoria Baldia: los tojolabales y las fincas, testimonios, UNAM, México.

—, 1996, 'El lu'umk'inal o espacio terrestre y sus moradores según los tojolabales. Los 'vivos' y los 'cabezas de piedra' en el espacio terrestre”, en Anuario de Estudios Indígenas Й, San Cristóbal de Las Casas, Chiapas, IEI- UNICACH.

Gorza, Piero, 2000, "El anhelo de conservar y la necesidad de perderse: 'cortacabezas' en San Pedro Chenalhó, Chiapas, México, 1996" en Witold Jacorzynski (coordinador): Estudios sobre la violencia. Teoría y práctica. CIESAS, México.

Fernández Liria, Carlos, 1992, "Enfermedad, familia y costumbre en el periférico de San Cristóbal”, en Anuario 1992, Instituto Chiapaneco de Cultura, México.

Foucault, Michel, 1981, Un diálogo sobre elpoder. Alianza, Madrid. Freyermuth, Graciela, 2000, "Violencia y etnia en Chenalhó. Formas comunitarias de resolución de conflictos" en Witold Jacorzynski (coordinador): Estudios sobre la violencia. Teoría y práctica. CIESAS, México.

Geertz, Clifford, 1990, La interpretación de las culturas. Gedisa, Barcelona.

Calixta Guiteras H., 1961, Los peligros del alma. Visión del mundo de un tzotzil, FCE, México.

Hermite, Esther, 1970, Control Social y poder sobrenatural en un pueblo maya contemporáneo, Instituto Indigenista Interamericano, México.

Köhler, Ulrich, 1977, Chombilal ch'ulelal-Alma perdida, UNAM, México.

Lenkersdorf, Carlos, 1996, Los hombres Verdaderos. Voces y testimonios tojolabales. Siglo xxi, México.

—, 1979, Diccionario tojol ab'al españoly español tojol ab'al. 2 vols. México, Ed. Nuestro Tiempo, México.

Lisbona Guillén, Miguel, 2003, “'Otras voces, otros tojolabales. La pluralidad de una comunidad inventada", ponencia para el encuentro Pueblos y Fronteras 2003. La comunidad a debate. Reflexiones sobre el papel de la comunidad en el México contemporáneo. PROIMMSE-IIA-UnAm, San Cristóbal de Las Casas, octubre de 2003.

Montagú, Roberta, 1970, “Autoridad, control y sanción social en las fincas tzeltales" en Ensayos de antropología en la zona central de Chiapas. Norman McQuown-Julian Pitt-Rivers (eds.), INICNA, México. 
Pitarch Ramón, Pedro, 1994, Ch'ulel. Etnografía de las almas tzeltales. FCE, México.

Pinto Durán, Astrid, 2000, Los Artificios de la fidelidad. Reciprocidad y poder en una finca de los Altos de Chiapas, CESMECA-UNICACH, México.

—, "Muerte por Sortilegio. Brujería, nagualismo y reciprocidad negativa en una finca de Los Altos de Chiapas" en Anuario 2000, CESMECA-UNICACH, México.

Ruz, Mario H., 1992 [1983], Los legitimos hombres. Aproximación antropológica al grupo tojolabal. Vol. II, IIE. UNAM, México.

Sahlins, Marshall, 1976, Cultura y razón práctica. Gedisa, Barcelona

—, 1989, Islas de Historia: la muerte del capitán Cook. Metáfora, antropología e historia. Gedisa, Barcelona.

Salamanca, Carlos A. y Florencia C. Tola, 2002, "La brujería entre los tobas del Chaco argentino" en Desacatos. Transgresiones. Primavera-Verano 2002, CIESAS, México.
Thomas, Norman D., 1974, Envidia, brujería y organización ceremonial. Un pueblo zoque. SEPSETENTAs, México.

Thompson, John B., 1994, Ideología y cultura moderna. UAM, México.

Van Der Haar, Gemma, 1998, "La campesinización de la zona alta tojolabal: el remate zapatista" en Espacios disputados: ransformaciones rurales en Chiapas, UAM-ECOSUR, México.

Viqueira, Juan Pedro, 1995, "La comunidad india en México en los estudios antropológicos e históricos”, en Anunario 1994, CESMECA, México.

—, 2002, Encrucijadas Chiapanecas. El Colegio de México, Tusquets. México.

Villa-Rojas, Alfonso, 1963, "El nagualismo como recurso de control social entre los grupos mayances de Chiapas" en Estudios de cultura maya, México.

Jacorzynski, Witold, 2000, “Sacrificio, capital y violencia. Temas simbólicos de la narrativa sobre 'cortacabezas' en Los altos de Chiapas” en Witold Jacorzynski (coordinador): Estudios sobre la violencia. Teoría y práctica. CIESAS, México. 